\title{
Ancestral Home of Indo-Aryan Peoples and Migration of Iranian Tribes to Southeastern Europe
}

\author{
Saydali Mukhidinov *
}

Department of History and International Relations, Russian-Tajik Slavonic University, M.Tursunzoda str., 30, Dushanbe, 734025, Tajikistan

\begin{abstract}
The article attempts to clarify and analyze the opinions, hypotheses, ideas and assumptions of scientists studying the issues of ancestral home of the Indo-Aryan peoples from the historical, archaeological and linguistic points of view. The Eastern European localization of the ancestral home of the Indo-Aryan peoples in Southeastern Europe and their migration is considered in the article. The territory of Central Asia was occupied by the Iranian nationalities in the beginning of the historical period (VII-VI centuries BC): Bactrians, Sogdians, Khorezmians, Parthians, Saka tribes. The analysis of relict phenomena in the languages and culture of modern population of Central Asia, in particular the population of the Pamirs, shows the presence of an ancient Indo-Aryan layer. In this case, a specific convergence is identified, which is precisely oriented on the ancient Indian tradition. At the same time, even more ancient traces associated with the pre-Indo-Iranian population of Central Asia are revealed. The substrate layer played a huge role in the genesis of the culture, ideology and ethnos of the most ancient Iranian-speaking population of Central Asia. It had a huge impact on the establishment of its social and economic basis.
\end{abstract}

\section{Introduction}

In the XX century, Soviet and foreign scholars had been mainly studying the issues of ancestral home of the IndoAryan peoples. There were revealed many hypotheses and assumptions in relation to this issue; books and articles were published, various scientific events were held. However, national self-awareness, and the study of both cultural and historical values of ancestors obliges us to go back to the sources and once again present these values to the modern generation.

The importance of such study relates to the current situation in the world influenced by political, economic, cultural and moral crises; young people and the younger generation must be aware of the roots of their ancient civilization, the language and culture of their people.

\subsection{Problem Statement}

The issue of the ancestral home of the Indo-Aryan peoples and migration of Iranian tribes to Southeastern Europe is an urgent research task as it allows to determine the value of Central Asian civilization for the spread of the subsistence economy in Eastern Europe.

\subsection{Purpose of Study}

The purpose of this article is to study and analyze the opinions, hypotheses, ideas and assumptions of scientists who study this problem from the historical, archaeological and linguistic points of view. To achieve this goal, the following has to be done:

- To identify the main issues relating to the study of ancestral home of the Indo-Aryan peoples.

- To determine the territories of the spread of Iranian languages and tribes in ancient times.

- To study the hypotheses and judgments of linguists, basing on linguistic data about the oldest migrations of the Indo-Iranian peoples from Southeast Europe.

\subsection{Research Methods}

The historical - comparative method is applied in this study. This method allows us to reveal the essence of the phenomena under study on the basis of the available facts in those cases when it is not obvious; to identify the general and the repetitive, necessary and legitimate, on the one hand, and qualitatively different on the other hand. In this way, the existing gaps are filled and the study is completed. In the case when the subject matter similarity is established, an analogy is applied. An analogy is a correspondence or partial similarity. Thus, the comparison is an important and, perhaps, the most common method of scientific cognition.

\section{Results and Discussion, Findings}

In the opinion of the Tajik scientist, academician M.S. Asimov [1] one of the most 'critical' stages in the history of Central Asia, i.e. the 2nd millennium BC, was the end of the Bronze Age, when there appeared an opportunity for the development of iron metallurgy. Besides, the important economic, social and cultural

\footnotetext{
*Corresponding author: raja1956@mail.ru
} 
changes took place. The pivotal characteristic of that time was an intensification of ethnic processes, which involved not only local population, but also tribes and groups of tribes from very remote areas. Ethnic processes in the Central Asia, i.e. the 2nd millennium $\mathrm{BC}$ were very global (in the scale of the oecumene of that time). In the historical perspective, the significance of these ethnic processes is enormous. It should be noted that the ethnic substrate of peoples populating Central Asia was established at that time. Considering the opinions of various scholars regarding the idea of Eastern European localization of the ancestral home of the Indo-Aryans it can be concluded that the ancestral home of the Indo-Aryan peoples should be sought in the Southeastern Europe. The Indo-Aryans, the WestIranians, and finally the East-Iranian tribes subsequently moved from that location. The latter in the beginning of the historical period inhabited a large part of Central Asia [1].

Further on, a part of the Indo-European tribes, namely the Indo-Aryan tribes (placed in the diagram of T.V. Gamkrelidze and V.V. Ivanov) settled in the eastern part of the Indo-European dialect range, i.e. in the northern part of the Iranian plateau. Their first migration passed to India from here through Afghanistan (intermediate waves left their trace in the Dardan languages). The West Iranian tribes moved south from the northern part of the Iranian highlands. The Eastern Iranians remained relatively long in the original territory. And in their dialects there were a number of words and expressions close to the common Indo-European. Then they began to migrate through Central Asia (where they partially remained) and through the Caspian steppes of the North Caucasus and the Black Sea region. Part of it went east to Altai [1]. This issue was considered in the works of other scientists, most of whom support this opinion.

According to the assumptions of academician B.G. Gafurov, in ancient times the area of distribution of Iranian languages and tribes was much more extensive than in the Middle Ages and modern times. It stretched from Southeast Europe to eastern Turkestan and from the Urals and Southern Siberia to the south of Iran. Ancient sources directly testified the migration of groups of Iranian-speaking tribes from the east to the Southeastern Europe in the area to the north of the Caucasus and the Black Sea. According to him, these were the Scythians, who came here in the IX-VII centuries BC. Some of the Scythians moved through the Caucasus to the Near East, and then through the Sarmatian-Alanic tribes. Among the latter there were the ancestors of one of the most significant modern Iranian peoples, i.e. Ossetians, who currently live in the Caucasus. As evidenced by written sources and archaeological data, before they moved westward the center of the Sarmatian tribes was considered the territory in the north of the Caspian and Aral Sea to the Trans-Urals. Thus, it was historically and archaeologically recorded that the Iranian tribes migrated to Southeastern Europe from the east of the Volga river and the Urals. Moreover, the Iranian tribes had lived in these areas long before the beginning of the 1 st millennium BC [2]. Then the historical path that had been traversed for many millennia by the peoples of the Central Asia attests to the enormous significance of social and economic, political and cultural processes that took place in the history of civilization, as these countries were in the cutting-edge of the historical development [2]. Basing on the history and archaeological findings, the migration of Iranian tribes to the Southeast Europe had been witnessed from the regions east of the Volga river and the Black Sea. The Iranian tribes could only get to the territory of East Turkestan (including the ancestors of the Hotanosak language) from the Central Asia or Eastern Kazakhstan. In the beginning of the historical period (VII-VI centuries BC) the territory of Central Asia was occupied by Iranian nationalities: Bactrians, Sogdians, Khorezmians, Parthians, Saka tribes, etc. [5]. The data presented indicates that the process of migration of Aryans started in the middle or in the second half of the 2nd millennium BC from the Central Asia to the south, including India and its territory. In XII $-\mathrm{X}$ centuries BC the Aryan tribes were already supposed to be in India (the date of the Rigveda) [2].

Another scientist, academician N.N. Negmatov divides the ancestral homes of the Aryans in the historical and cultural areas. In particular, he notes that at the turn of the II-I millennium BC the lands of the ancestral homeland of the Aryans were divided into a number of highly developed historical and cultural areas: Margiana with the capital of Merv, the southern courses of Murgab and Tejen and the northern foothills of Kabutak (north Khorasan mountains). Bactria with the capital of Balkh - in the basin of the Middle and Upper Amu Darya, between the Hindu Kush and the Gissar range; Sogdiana with the capital of Samarkand - in the basins of the Zarafshan, Kashkadarya, Syrdarya and Khaftrud river; Khorezm - in the basin of the lower Amu Darya and Southern Pripamiry; Areia (Kharayava) the capital of Hirat - in the basin of the river Helmand and Malom Khorasane. All these areas (dahyu) are listed in the edited revisions of Avesta. The population, i.e. the ethnic groups of several isolated Aryan regions spoke the Aryan-Avestan language with few differences in a dialect. They all formed the eastern group of the ancient Iranian (Aryan) languages of historical Ariana, and when the Tajik people were formed in the era of the Samanid state (V-X AD) they became part of the language as the main ethno-linguistic components [3].

From the historical, archaeological and linguistic points of view the opinions of many scholars coincide in the sense that the ancestral home of the Indo-Aryan peoples can be sought in Southeastern Europe.

A great scientist in the field of linguistics V.I. Abaev [4], relying solely on the linguistic data puts forward a number of arguments in favor of his hypothesis on the ancestral home and the ancient migrations of the IndoIranian peoples. According to him, the evidence of the Eastern European ancestral home of the Indo-Iranian tribes, the name of the Volga at Ptolomei takes place: Ra. It is compared with the Vedic Rasa, Avest Ranha, and 'the name of the mythical river'. The meaning of the 'mythical river' suggests that the Vedic and Avestan people during the creation of the Rigveda and Avesta 
lived far away from the Volga river and only vague memories were stored about it [4]. Continuing his thought, he writes that this material allows us to advance the point, i.e. Southeast Europe shall be taken as a focal point in all assumptions and hypotheses about ancient migrations of the Indo-Iranian peoples. The earliest indication of such migration is evidenced by the ProtoIndian language from the Near East dating back to the middle of the 2nd millennium BC [4]. In the second half of the second millennium BC the Iranian community, remaining on the territory of the ancestral home, was inhomogeneous from the dialect point of view. The Kimmero-Scythian group, which occupied the western part of the area at that time, had separate contacts with the European languages that left their mark in the Ossetian, Saka, Afghan and Pamirian languages, which are associated with this group [4]. From the beginning of the I millennium BC the Iranian world was represented by two vast areas: the northern one from the lower Danube and the Prut to the Aral Sea, and the southern area, the Asiatic from the Arax and Urmia to present-day Turkmenia. The first community included future Kimmerians, Scythian - Sarmatians, Khorezmians, Sogdians, Avestians, Bactrians. The second community was comprised of the future Medes, Persians, Kurds, Baluchis. The Parthians occupied an intermediate position. Between these two groups some linguistic discrepancies have emerged on the basis of common ancestral home, which may have been deepened as a result of complete territorial fragmentation [4]. As it has already been said the differences in dialects and territorial division within the Northern Iranian group had been identified by the end of the $2^{\text {nd }}$ millennium BC. By that time Proto-Bactrians and Protosogds had moved to Central Asia. The Kimmer-Scythian-Sarmatian tribes who led a nomadic and semi-nomadic way of life were very mobile. They traveled to the Caucasus, Asia Minor, as well as Central Asia and back. One of such 'reverse movements' from Central Asia to Europe in VII or VIII centuries BC was mistakenly interpreted as the first appearance of the Scythian and Iranian element in Europe (historical tradition of Herodotus). The Ossetian-European isoglosses, dating back to the 2nd millennium BC demolish this view [4].

The Afghan and Pripamir languages reveal certain traits that successively link them to the Saka language. However, none of them can be considered its direct descendant. They should be considered as a result of mixing Proto-Saka with other Iranian dialects in Central Asia, Bactrian and others. Some non-Iranian languages such as Vershiksk language could also take part in their formation. According to V.I. Abaev, the chronological outline of the ancient destinies of the Indo-Iranian tribes can be presented in the following way: on the 2nd half of $3^{\text {rd }}$ millennium BC the Indo-European community started to disintegrate. The Proto-Greeks, Proto-Hitts and ProtoArmenians moved to the south, to the Balkan Peninsula and to Asia Minor. The Indo-Europeans remaining on the territory of the ancestral home formed two great communities: the Central European, being part of future Slavs, Balts, Tochars, Germans, Celts, Italics, and the Aryan in Southeast Europe. The Aryan community had contacts with the Finno-Ugric peoples. The first half of the $2^{\text {nd }}$ millennium $\mathrm{BC}$ : the Aryan community was divided into two branches, the Proto-Iranian and the Proto-Indian. The latter left the territory of Europe and passed through Western Asia to India. The Proto-Indian components in the Akkadian and Hittite texts of the middle of the $2^{\text {nd }}$ millennium $\mathrm{BC}$ should be regarded as traces of this migration. The end of the II millennium BC and the beginning of the $1^{\text {st }}$ millennium BC: the Iranian society is divided into two groups one of which is the Kimmer-Scythian, including Proto-Sogdians, ProtoBactrians and some other tribes, and Proto-Midopersian. The latter passed through the Caucasus to the south and occupied the Iranian plateau. There were two large Iranian-speaking areas, the northern one in SouthEastern Europe and the adjacent regions of Central Asia, and the southern one, between the Caspian Sea and the Persian Gulf [4].

The first half of I millennium BC: some part of the Scythians, being part of a large tribe of Proto-Saka had separated away from the main Scythian massif and extended far to the east, to the borders of China. At the same time, Bactrians, Sogdians and some other tribes, belonging to the same northern group of Iranianspeaking peoples had settled in Central Asia. In VIII-VII centuries BC a part of the Scythian tribes, which had formerly left Southeastern Europe to Central Asia, moved in the opposite direction and pressed its Cimmerians relatives. Many things have to be developed on the basis of hypotheses. In this case the hypotheses are legitimate if they do not contradict to each other and, in addition, if they are economical. During this study the authors tried to keep within the framework of noncontradictory and economical hypotheses [4].

Referring to the methodology of studies on ethnic history the researcher I.M. Dyakonov [5] gives the example of Cimmerians, showing that after the defeat of the Cimmerians by their allies the Cimmerians disappear from the pages of history not only in the Near East, but also in the Black Sea region. Herodotus believes they were squeezed out by the Scythians from the very beginning, moving backwards towards the main direction of the Indo-Iranian tribes' movement, i.e. from the Volga river in the Black Sea region [5]. According to E.K. Kuzmin [6], the Andron and Srubna cultural communities, formed in the second quarter of the $2^{\text {nd }}$ millennium $\mathrm{BC}$ as a result of the movement, integration and assimilation of different cultures can be considered as a result of migration of the second type [6]. According to academician B.A. Litvinsky [7], the analysis of relict phenomena in languages and culture of the modern population of Central Asia, in particular, the population of the Pamirs, shows the presence of an ancient IndoAryan layer. In this case, a specific convergence is identified (orientation on the ancient Indian tradition). At the same time, even more ancient traces associated with the pre-Indo-Iranian population of Central Asia are revealed (cosmological representations, the cycle 'goattree- celestial fairy', the cult of fire, the cult of cattle, etc.). The substrate layer played a huge role in the formation of the culture, ideology and ethnos of the most ancient Iranian-speaking population of Central Asia, as 
well as it had a huge impact on the formation of social and economic basis [7]. According to B.P. Alekseev [8], the largest group of the Iranian peoples was the carrier of different combinations of morphological characters. Among such people there were Persians, Pashtuns, Kurds, and Tajiks. A special issue refers to the belonging of Pamir peoples to this complex. This concept is interpreted in a broad sense, meaning that peoples and ethnographic groups that lived not only within the USSR, but also in the territory of Northeastern Afghanistan are included in this complex [8]. According to the conclusions of this author, in the light of paleoanthropological and anthropological data the ancestral home of the Indo-Aryans is delineated within a vast area that encompasses the south of Central Asia and the Iranian highlands. The boundaries of the ancestral home in the west and the east are not very distinct; however, it seems to be probable, basing on a sharp drop in landscape features and extra-anthropological considerations (the successful decoding of inscriptions from Mohenjo-daro based on Dravidian languages, that the eastern border did not go beyond the Indus valley) [2]. Studies of A. Bart [9] are of great interest as the investigations of the ethnogenetic processes showed that the language is the most reliable ethnic indicator. It can be argued that a language is the only ethnic indicator (author's italics, S.M.). Toponymy is part of the history of language families. Chronological and ethnic stratigraphy of toponyms, identification of toponymic formats, characteristic of individual language families is an important source for determining the ancient territories of distant ancestors of the peoples of language families. Y. Harmatta showed about 50 words of the Indo-Iranian origin in the Finno-Ugric languages. The importance of these words is explained primarily not by the manifestation of quantitative laws, but by their character. They refer to culture and social organization. The terms of agriculture are particularly important [9]. The oldest layer of Hungarian agricultural vocabulary refers to the oldest period of the Indo-European borrowings, possibly, to the $2^{\text {nd }}$ millennium $\mathrm{BC}$. The carriers of the subsistence economy at that time came to the territory of the Volga-Kamia (Srubna, Abashev, Balanovo, Volosovo, Fatyanovo cultures). The homeland of agriculture is where the wild ancestors of cereals grow. Central Asia is one of the centers of genesis and distribution of agriculture. By all accounts, Central Asian civilizations were of great importance for the spread of the subsistence economy in Eastern Europe. Ancient Hungarian culture, in many respects, had connections with Central Asia and experienced the influence of Central Asian civilizations. Great Hungarian composers and musicologists B.Bartok and Z.Kolai noted that Hungarian folk music is the most western branch of the great Asian musical culture, and the musical language of the people is as revealing as the phonetic language [9]. According to the ethnographer $\mathrm{Z}$. Madaminjanova, the ancient Tajik languages among which are Bactrian, Sogdian, Margian (a kind of Bactrian) belong to the eastern group of Middle Iranian languages. But the Bactrian is the southeastern subgroup or the Saka-Vakhan subgroup, its relics are the Pamir languages. The Sogdian is the northeastern subgroup or the Scythian-Ossetian (more precisely, the SakaSarmatian-Osetian), its relic is Yagnob. Naturally, the people who had a single language also had a common ritual based on a single religion, i.e. zoroastrianism, where the four natural elements like Earth, Air, Water and Fire were revered. The entire ritual system of the Tajiks was formed during this ancient period and their ancestors were the authors of these rituals. Thus, Z.Madaminzhanova concludes, since the ancestors of Tajiks were sedentary farmers and showed a weak tendency to resettlement and migration it can be assumed that the ritual tradition with some innovations has survived to the present day.

Central Asia has always attracted attention, there have been conquests of territories by other peoples, as a result of which the population of Central Asia was represented by various peoples. In this territory, sedentary agricultural and nomadic pastoral peoples coexisted with each other, different in ethnic history, culture, traditions, ways of life, mentality, values and wealth. Geographical and social factors, as well as the existing infrastructure forced the pastoralists to live in limited areas of nomadic life, while the indigenous population, i.e. settled farmers were locked in the oases and mountain valleys [10].

The migration of Iranian-speaking tribes from the east to the Southeast Europe ad to the north of the Caucasus and the Black Sea remains to be a major problem for the scientific studies. The Scythians, Sarmatians and other tribes, like the ancient Sogdians the ancestors of the Tajik people, were Iranian-speaking and penetrated into the territory of the Crimea. One of the purposes of this study was to clarify who out of all these peoples and tribes visited these regions making through the Scythian-Saka Way. Who participated in the establishment of port cities of Crimea including Sudak? Basing on the assumptions and guesses it is thought that Sogdian merchants arrived in this city through the Scythian-Saka path and not only participated in its construction, but also created their trading factories.

\section{Conclusion}

The issue of the ancestral home of the Indo-Aryan peoples and their migration from the east to Southeastern Europe in the region to the north of the Caucasus and the Black Sea is still one of the most important issues, and not only from the historical point of view. In the opinion of most Soviet and modern linguists the homeland of the Indo-Aryan peoples should be sought in Southeastern Europe. They were subsequently leaving the territory, i.e. first the Indo-Aryans, then the West-Iranian and, finally, the East-Iranian tribes. In the beginning of the historical period (VII-VI centuries BC) the territory of Central Asia was occupied by the Iranian nationalities: Bactrians, Sogdians, Khorezmians, Parthians, Saka tribes, etc. Thus, it was historically and archaeologically evidenced that the Iranian tribes migrated to Southeastern Europe from the regions east of the Volga river and the Black Sea. From the beginning of the I millennium $\mathrm{BC}$ the Iranian world was represented by 
two vast areas: the northern one from the lower Danube and the Prut to the Aral Sea, and the southern area, the Asiatic from the Arax and Urmia to the present-day Turkmenia.

By all accounts, Central Asian civilizations were of great importance for the spread of the subsistence economy in Eastern Europe. For example, the ancient Hungarian culture in many respects had connections with Central Asia and experienced the influence of Central Asian civilizations.

\section{References}

1. M.S. Asimov, Study of the ethnic history of ancient Central Asia (2nd millennium BC) in Soviet science, Ethnic problems of Central Asia in the ancient times (II millennium BC). (Moscow: Nauka, 1981)

2. B.G. Gafurov, Some issues of the ethnic history of peoples of Central Asia in the earliest period. Ethnic issues of Central Asia in the ancient times (2nd millennium BC). (Moscow: Nauka, 1981)

3. N.N. Negmatov, The ancestral home of the Aryans (Dushanbe, 2005)

4. V.I. Abaev, On the issue of the ancestral home and the oldest migrations of the Indo-Iranian peoples, Ancient East and the Ancient World: Collected papers, Moscow: Publishing House of Moscow University, pp. 26-37 (1972)
5. I.M. Dyakonov, To the background of ethnic history studies (Cimmerians), Ethnic problems of Central Asia in ancient times (2nd millennium BC). (Moscow: Nauka, 1981)

6. E.E. Kuzmina, The origin of the Indo-Aryans in the light of the latest archaeological data, Ethnic problems of Central Asia in antiquity (2nd millennium BC). (Moscow: Nauka, 1981)

7. B.A. Litvinsky, Problems of the ethnic history of Central Asia in the II millennium BC. (Central Asian aspect of the Aryan problem), Ethnic problems of Central Asia in acient times (2nd millennium BC). (Moscow: Nauka, 1981)

8. V.P. Alekseev, Anthropological aspects of the IndoAryan problem, Ethnic problems of Central Asia in antiquity (2nd millennium BC). (Moscow: Nauka, 1981)

9. A. Bart, Uralic peoples and civilizations of Central Asia and the millennium BC, Ethnic problems of Central Asia in ancient times (2nd millennium BC). (Moscow: Nauka, 1981)

10. Z. Madaminzhanova, The ritual tradition of Tajiks in the light of transformational ethnic processes in Central Asia, A series of open lectures on the thematic block Interdisciplinary Discourse in the Context of Relationship between Humanitarian and Natural Science Research. (Dushanbe, 2015) 